\title{
Nanoclusters of Cyanuric Acid ${ }^{\dagger}$
}

\author{
M ELANGO $^{\mathrm{a}, \mathrm{b}}$, V SUBRAMANIAN $^{\mathrm{a}, *}$ and N SATHYAMURTHY ${ }^{\mathrm{c}, \mathrm{d}, *}$ \\ ${ }^{a}$ Chemical Laboratory, CSIR-Central Leather Research Institute, Adyar, Chennai 600 020, India \\ ${ }^{\mathrm{b}}$ Department of Chemistry and Biochemistry, University of Arizona, Tucson, Arizona 85721, USA \\ 'Indian Institute of Science Education and Research Mohali, Sector 81, SAS Nagar, \\ Manauli P.O. 140306, India \\ dJawaharlal Nehru Centre for Advanced Scientific Research, Bangalore 560 064, India \\ Email: subuchem@ hotmail.com; nsath@iisermohali.ac.in
}

MS received 5 December 2016; revised 2 March 2017; accepted 3 March 2017

\begin{abstract}
In this article, the self-assembly of cyanuric acid (CA) molecules into nano-structures is examined. Equilibrium geometry of CA is planar and it belongs to the $D_{3 \mathrm{~h}}$ point group. It is shown that CA clusters form three dimensional bowls and balls. Cyclic pentamer (5-bowl) is the basic motif responsible for these non-planar geometries. It is also shown that the cyclic hexamer based clusters can be non-planar if they contain a 5-bowl. A unified criterion for the formation of bowls and balls from basic molecular building blocks emerges from this study. The role of symmetry in supramolecular self-assembly is also clearly evident from the present study.
\end{abstract}

Keywords. Hydrogen bonding; molecular clusters; cyanuric acid; self-assembly; symmetry.

\section{Introduction}

Supramolecular self-assembly is a strategy for organizing various structural motifs into novel molecular structures on a large scale. ${ }^{1-4}$ Due to its strength, directionality and biological relevance, hydrogen bonding (H-bonding) is one of the most important interactions leading to self-assembly and thus in the formation of supramolecular structures..$^{5-7}$ It is evident from the studies on H-bonding interaction in various fields that it has an optimal combination of rigidity and flexibility as well as directionality. ${ }^{5-7}$ Therefore, it serves a unique role in the self-assembly of various molecular clusters. With the help of $\mathrm{H}$-bonding interaction, it is possible to design bowls, balls and tubes of orthoboric (BA) and metaboric (MBA) acid clusters akin to the carbon based fullerenes and nanotubes. ${ }^{8-10}$ In this context, a systematic search has been made to identify a molecular building block that could self-assemble to form bowls and balls similar to BA and MBA. Cyanuric acid (CA) has a plane of symmetry perpendicular to the $C_{3}$ principal axis. It also has got self-complementary $\mathrm{H}$ bonding regions. Therefore, it is worth exploring the formation of bowls and balls from CA clusters. This particular molecule has received considerable attention

\footnotetext{
*For correspondence

${ }^{\dagger}$ Dedicated to the memory of the late Professor Charusita Chakravarty.
}

in supramolecular chemistry. ${ }^{11}$ It is a unique cyclic amide having three $\mathrm{H}$-bond donor and three acceptor sites that facilitate the formation of $\mathrm{H}$-bonded structures with itself and with other polar molecules. It is structurally similar to amino acids and hence serves as a model system to study non-covalent interactions in the self-assembly of molecules of biological interest.

Various experimental and theoretical studies have been made to understand the structure of $\mathrm{CA}$ and its keto-enol tautomerism. ${ }^{12}$ These studies have clearly shown that the keto form is more stable than the enol form. The 1:1 hydrogen-bonded complex of CA and melamine has been studied in detail with a view to understand the underlying principles of molecular selfassembly, and its potential applications for development of molecular devices at nanoscale. ${ }^{11,12}$ Recently, the self-assembly of CA into ordered nanostructures on a crystalline substrate has been investigated at low temperature under ultrahigh vacuum (UHV) conditions using scanning tunneling microscopy and theoretical simulation methods. ${ }^{13,14}$ Different structural motifs of CA that can self-assemble into different patterns and superstructures have been reported (see Figure 1). They are: the hexamer (rosette), the heptamer (wheel), and the chicken-wire-like structures. The aim of the present study is to predict whether CA would also form bowls and balls similar to BA and MBA with a view to develop new molecular materials at nanoscale. 


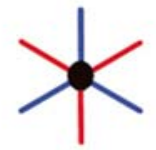

$\mathrm{CA}$
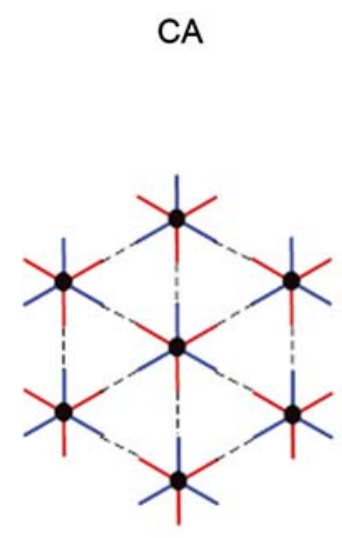

Heptamer (Wheel)<smiles>CO[C@@H](N)C(O)O</smiles>

Type-I

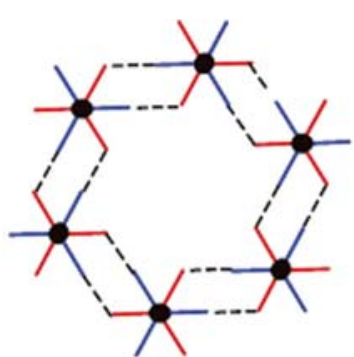

Hexamer (Rosette)

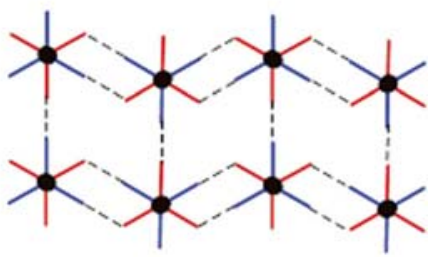

\section{Chicken wire}<smiles></smiles>

Type-II

Figure 1. Repeating units of polymorphs of cyanuric acid. Two types of H-bonding interactions in crystal structures of cyanuric acid are illustrated. The grey lobes represent lone pairs of electrons. Dotted lines represent H-bonding interactions.

\section{Theoretical and Computational Methods}

Geometries of $(\mathrm{CA})_{\mathrm{n}=1-24}$ clusters have been optimized without any constraint at DFT(M062X)/6-31G*, DFT(M062X)/6-311++G** and HF/6-31G* levels of theory using the G09 suite of programs. ${ }^{15}$ Additional calculations have been carried out at the MP2/6-31G* level of theory for $(\mathrm{CA})_{1,2}$ and DFT(B3LYP)/6-31G* level of theory for $(\mathrm{CA})_{1-6}$. All of them are found to be stable relative to the separated monomers. The stabilization energy (SE) of all the clusters has been calculated using the supermolecule approach and corrected for basis set superposition error (BSSE) following the procedure adopted by Boys and Bernardi: ${ }^{16}$

$$
S E=-\left(E_{\text {cluster }}-\sum_{i=1}^{n} E_{i}\right)
$$

where $E_{\text {cluster }}$ is the total energy of the cluster, $E_{i}$ is the energy of the monomer and $n$ is the total number of monomers in the cluster. Specifically, BSSE was estimated for each monomer in its location by computing its energy with its own basis set and with
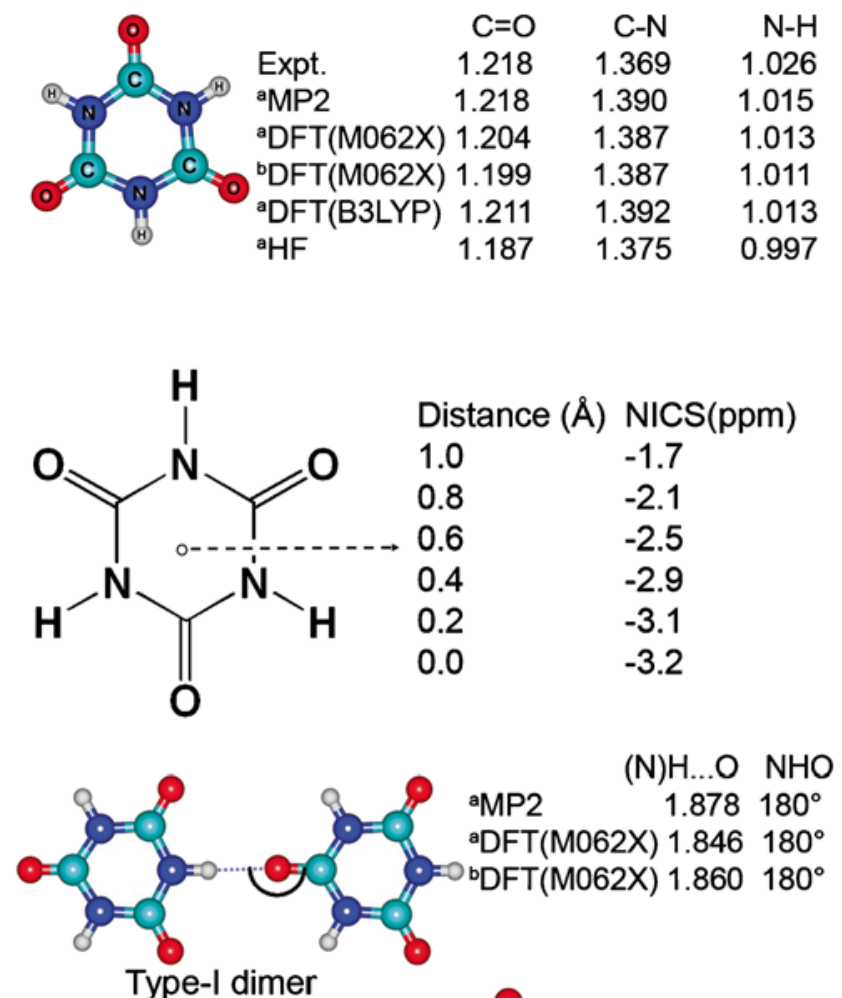

Type-I dimer

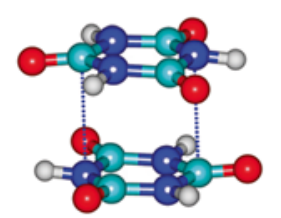

Stacked dimer

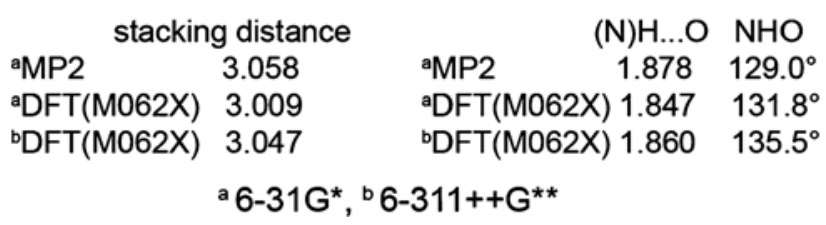

Figure 2. Geometrical parameters of cyanuric acid (CA) monomer obtained from HF, DFT(M062X), DFT(B3LYP) and MP2 calculations using the $6-31 \mathrm{G}^{*}$ and $6-311++\mathrm{G}^{* *}$ basis sets along with the experimental values. ${ }^{26,27}$ Predicted NICS values in ppm, from the center of the ring to $1 \AA$ above the ring obtained from MP2/6-31G* calculations are listed. Optimized geometries of stacked and hydrogen bonded CA dimers as obtained from MP2/6-31G*, DFT(M062X)/6-31G* and DFT(M062X)/6-311++G** calculations are shown in the lower panel. All values are in $\AA$ unless mentioned otherwise.

the basis set for the (n-1)-mer. Vibrational frequencies calculations were performed for the HF/6-31G* and DFT(M062X)/6-31G* optimized geometries to analyze the nature of the complexes (minimum or transition state) and were used to account for zero point energy (ZPE) corrections. Vibrational frequencies obtained from $\mathrm{HF} / 6-31 \mathrm{G}^{*}$ were scaled ${ }^{17,18}$ by a factor of 0.8929 for comparison with the available experimental results. 

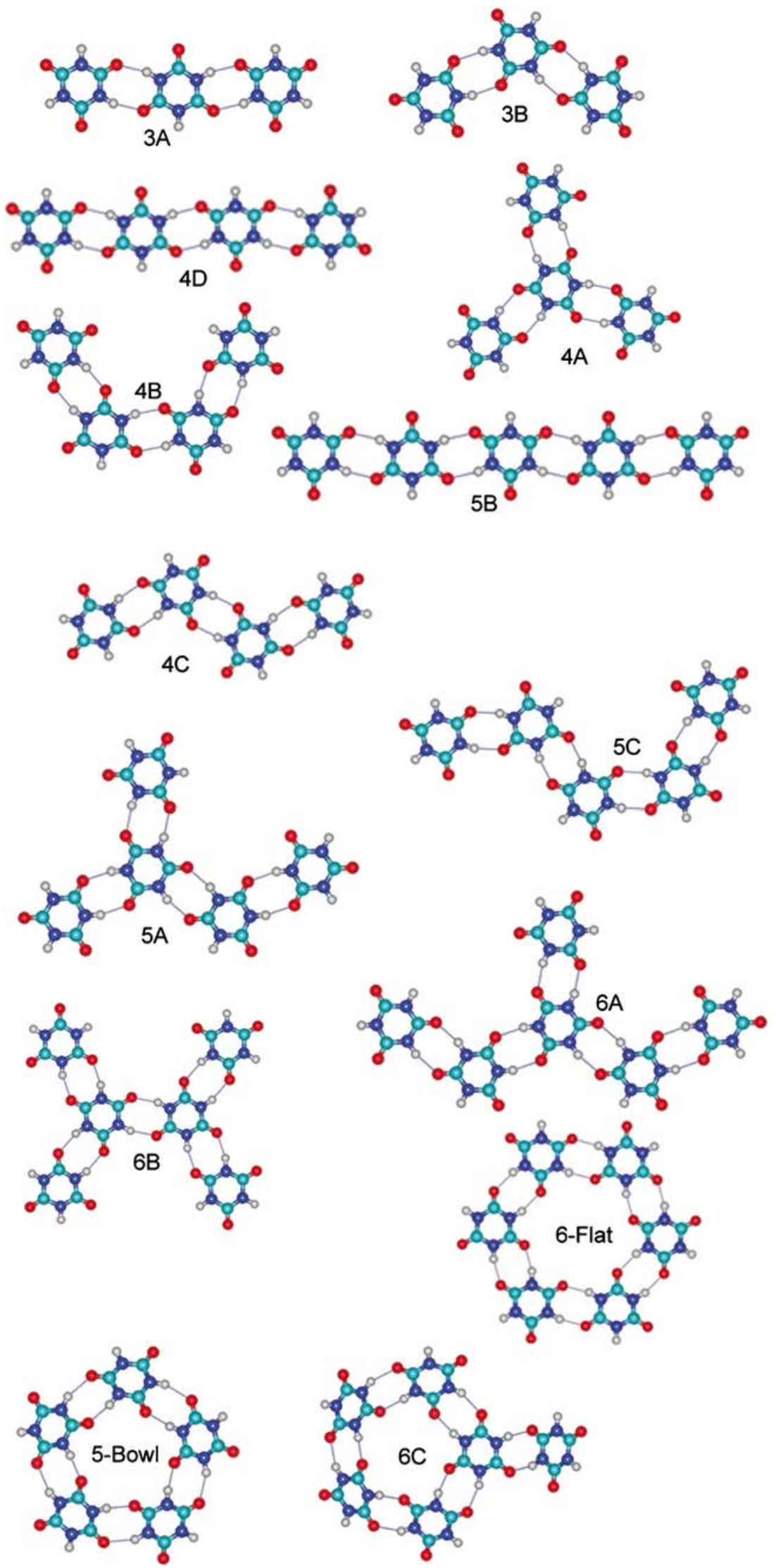

Figure 3. Optimized geometries of $(\mathrm{CA})_{n=3-6}$ clusters obtained from DFT(B3LYP)/6-31G* calculations. 
The theory of atoms-in-molecules (AIM) has been used to characterize the H-bonding and other non-bonding interactions between monomers using the topological properties of electron density at the hydrogen bond critical points (HBCPs) using the AIM2000 package. ${ }^{19,20}$ In addition, molecular electrostatic potential (MESP) maps $^{21,22}$ of the balls have been generated using Gauss View 3.0 software package. Nucleus independent chemical shift (NICS) values were calculated for the CA monomer at the MP2/6-31G* level using the procedure described elsewhere. ${ }^{23}$

\section{Results and Discussion}

\subsection{Structure and Stability}

The optimized geometry of CA monomer and dimer obtained from MP2/6-31G* calculations is shown in Figure 2 along with the geometrical parameters obtained from DFT(M062X)/6-31G*, DFT(M062X)/6$311++\mathrm{G}^{* *}$, DFT(B3LYP)/6-31G*, HF/6-31G* and MP2/6-31G* levels of theory. The equilibrium geometry of CA is planar and it belongs to $D_{3 \mathrm{~h}}$ point group. The computed $\mathrm{C}-\mathrm{N}, \mathrm{N}-\mathrm{H}$, and $\mathrm{C}=\mathrm{O}$ bond lengths, $1.390,1.015,1.218 \AA$, respectively at the MP2/6-31G* level of theory are in good agreement with the experimental values of $1.369,1.026$, and $1.218 \AA$, in that order. $^{24}$ It is worth adding that the geometrical parameters obtained from other methods are also comparable to the experimental values.

The aromatic nature of the CA ring has been examined by computing the NICS values that are included in Figure 2 for distances upto $1 \AA$ above the ring, as illustrated. The NICS values are less negative than for benzene implying that $\mathrm{CA}$ is less aromatic than benzene. It should be noted that the NICS calculations were performed at the MP2/6-31G* level.

It is clear from the crystal structure of CA that the molecules are held together by H-bonds in parallel sheet arrangement similar to that of graphite, boric acid and metaboric acid. An $\mathrm{N}-\mathrm{H}$ group of one $\mathrm{CA}$ molecule and a $\mathrm{C}=\mathrm{O}$ group of another are involved in $\mathrm{N}-\mathrm{H}$... $\mathrm{O}$ type $\mathrm{H}$-bond. Two types of $\mathrm{H}$-bonding interactions are observed in CA sheet structures as illustrated in Figure 1. These two H-bonds differ from each other in the direction of approach of the $\mathrm{N}-\mathrm{H}$ bond to the $\mathrm{C}=\mathrm{O}$ group. The type I H-bond has the $\mathrm{N}-\mathrm{H}$ bond collinear to $\mathrm{O}=\mathrm{C}$. The type II $\mathrm{H}$-bond has the $\mathrm{N}-\mathrm{H}$ bond directed at $\mathrm{O}=\mathrm{C}$ at an angle of $\sim 120^{\circ}$. Interestingly the $(\mathrm{N}-\mathrm{H}) \ldots \mathrm{O}$ distance in both types of interaction is $\sim 2.81 \AA$.

Table 1. Stabilization energy ( $\mathrm{SE}$ in $\mathrm{kcal} / \mathrm{mol})$ values for $(\mathrm{CA})_{\mathrm{n}=2-24}$ clusters.

\begin{tabular}{|c|c|c|c|c|c|}
\hline \multirow[b]{2}{*}{ Cluster } & \multirow{2}{*}{$\begin{array}{c}\mathrm{HF} \\
\text { 6-31G* } \\
\text { BSSE } \\
\text { corrected }\end{array}$} & \multicolumn{3}{|c|}{ DFT(M062X) } & \multirow[b]{2}{*}{$\begin{array}{c}\text { DFT(B3LYP) } \\
\text { 6-31G* } \\
\text { BSSE corrected }\end{array}$} \\
\hline & & $\begin{array}{c}\text { 6-31G* } \\
\text { BSSE } \\
\text { corrected }\end{array}$ & $\begin{array}{l}\text { 6-31G* } \\
\text { ZPE } \\
\text { corrected }\end{array}$ & $\begin{array}{c}\text { 6-311++G** } \\
\text { BSSE corrected }\end{array}$ & \\
\hline 2-type II & 10.1 & 13.5 & 14.1 & 13.4 & 12.3 \\
\hline $3 \mathrm{~A}$ & 20.8 & 26.9 & 28.2 & 26.6 & 24.3 \\
\hline $3 \mathrm{~B}$ & 20.2 & 27.0 & 28.1 & 26.7 & 24.5 \\
\hline $4 \mathrm{~A}$ & 30.4 & 40.7 & 42.8 & 40.3 & 36.7 \\
\hline $4 B$ & 30.3 & 40.6 & 42.3 & 40.2 & 37.0 \\
\hline $4 \mathrm{C}$ & 30.0 & 40.6 & 42.5 & 40.2 & 36.4 \\
\hline $4 \mathrm{D}$ & 30.2 & 40.3 & 42.1 & 39.9 & 36.6 \\
\hline 5-bowl & 46.9 & 65.3 & 67.5 & 63.5 & 57.7 \\
\hline $5 \mathrm{~A}$ & 37.2 & 53.2 & 56.5 & 53.7 & 47.9 \\
\hline $5 B$ & 37.6 & 53.3 & 56.0 & 53.2 & 48.1 \\
\hline $5 \mathrm{C}$ & 37.4 & 54.2 & 56.4 & 53.6 & 47.9 \\
\hline 6-flat & 60.7 & 81.3 & 86.0 & 80.5 & 73.9 \\
\hline $6 \mathrm{~A}$ & 50.0 & 67.9 & 70.8 & 67.2 & 60.6 \\
\hline $6 \mathrm{~B}$ & 51.8 & 68.0 & 71.2 & 67.3 & 61.3 \\
\hline $6 \mathrm{C}$ & 58.1 & 77.8 & 81.5 & 76.9 & 70.5 \\
\hline 7-bowl & 69.8 & 91.4 & 96.0 & 90.4 & - \\
\hline 8-bowl & 84.1 & 115.5 & 121.6 & 114.0 & - \\
\hline 10-bowl & 111.6 & 153.6 & 161.7 & 151.6 & - \\
\hline 12-bowl & 138.6 & 191.7 & 202.1 & - & - \\
\hline 14-bowl & - & 230.0 & 242.4 & 226.9 & - \\
\hline 15-bowl & 182.8 & 254.9 & 269.2 & 251.4 & - \\
\hline 18-bowl & - & 318.2 & 336.1 & - & - \\
\hline 20-ball & 269.4 & 380.4 & 403.2 & 374.9 & - \\
\hline 20-sheet & 243.7 & 326.1 & 342.7 & 321.7 & - \\
\hline 24-ball & - & 456.6 & 483.4 & - & - \\
\hline
\end{tabular}


The stacking interaction between two CA molecules has also been examined at MP2/6-31G*, DFT(M062X)/ 6-31G* and DFT(M062X)/6-311++ $\mathrm{G}^{* *}$ levels of theory. The stabilization energy for the $(\mathrm{CA})_{2}$ stacked dimer is $4.2 \mathrm{kcal} / \mathrm{mol}$. SE for the $(\mathrm{CA})_{2} \mathrm{H}$-bonded dimers with type I and type II interactions (see Figure 2) are 5.5 and $11.8 \mathrm{kcal} / \mathrm{mol}$, respectively. The SE of stacked dimer is comparable to that of type I dimer. But the SE of type II dimer is more than double that of the stacked dimer. SE values obtained from DFT(M062X)/6-31G* and DFT(M062X)/6-311++G** calculations are also in line with the MP2 results. Therefore, CA molecules can be expected to prefer self-assembly via hydrogen bonding interactions of type II.

Optimized geometries of $(\mathrm{CA})_{\mathrm{n}=3-6}$ clusters obtained from DFT(B3LYP)/6-31G* calculations are illustrated in Figure 3. It is evident from the figure that two different trimer geometries are possible for $(\mathrm{CA})_{3}$. They are designated as $3 \mathrm{~A}$ and $3 \mathrm{~B}$. Type II hydrogen bonding interactions are seen in $3 \mathrm{~A}$ and $3 \mathrm{~B}$ clusters. The stabilization energy values for $(\mathrm{CA})_{\mathrm{n}}$ clusters are listed in Table 1 . It can be seen that $3 \mathrm{~A}$ and $3 \mathrm{~B}$ are equally stable. A cyclic trimer cluster as shown in Figure 1, which is a part of the heptamer based sheet was not stable. All attempts to locate the minimized geometry resulted in a structure forming type II hydrogen bonds.

Different structures (4A, 4B, 4C and 4D) formed by $(\mathrm{CA})_{4}$ are also shown in Figure 3. Type II H-bonding is responsible for the formation of $4 \mathrm{~B}, 4 \mathrm{C}, 4 \mathrm{D}$ and $4 \mathrm{E}$. It is interesting to note from the structure of $4 \mathrm{~B}$ that the central CA molecule is $\mathrm{H}$-bonded to three other CAs in a triangular fashion. All the H-bonding donor and acceptor sites of the central CA are used, resulting in maximum stability. It can be observed from Table 1 that SEs of all $(\mathrm{CA})_{4}$ clusters are nearly the same.

Various structural arrangements are possible for $(\mathrm{CA})_{5}$. As observed in the case of $(\mathrm{BA})_{5}$ and $(\mathrm{MBA})_{5}$ in previous studies, ${ }^{8,9}$ the most stable geometry of the pentamer of CA is a bowl. The structural features of 5-bowl obtained from DFT(B3LYP)/6-31G* and DFT(M062X)/6-31G* levels of calculation are presented in Figure 4. The calculated radius of the central cavity is $3.183 \AA$ and the bowl depth is $1.709 \AA$. The corresponding values from M062X/6-31G* method are $3.254 \AA$ and $2.3 \AA$.

Different cyclic and linear structures of CA clusters are seen in the crystal structures. But the planar cyclic pentamer is not observed in any of the sheet structures. As observed in our previous studies on $(\mathrm{BA})_{5},(\mathrm{MBA})_{5}$ clusters, ${ }^{8,9}$ the present study also showed that the planar cyclic pentamer is a transition state of the bowl structure as depicted in Figure 4. The calculated inversion barrier is $2.8 \mathrm{kcal} / \mathrm{mol}$ at the DFT(B3LYP)/6-31G* level and
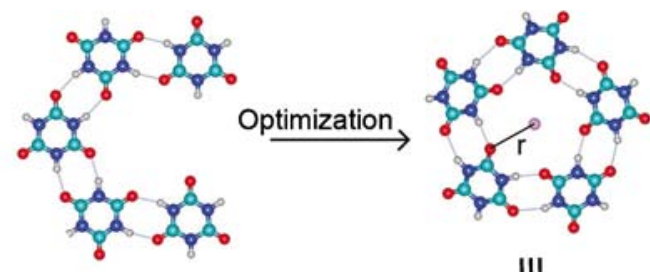

III
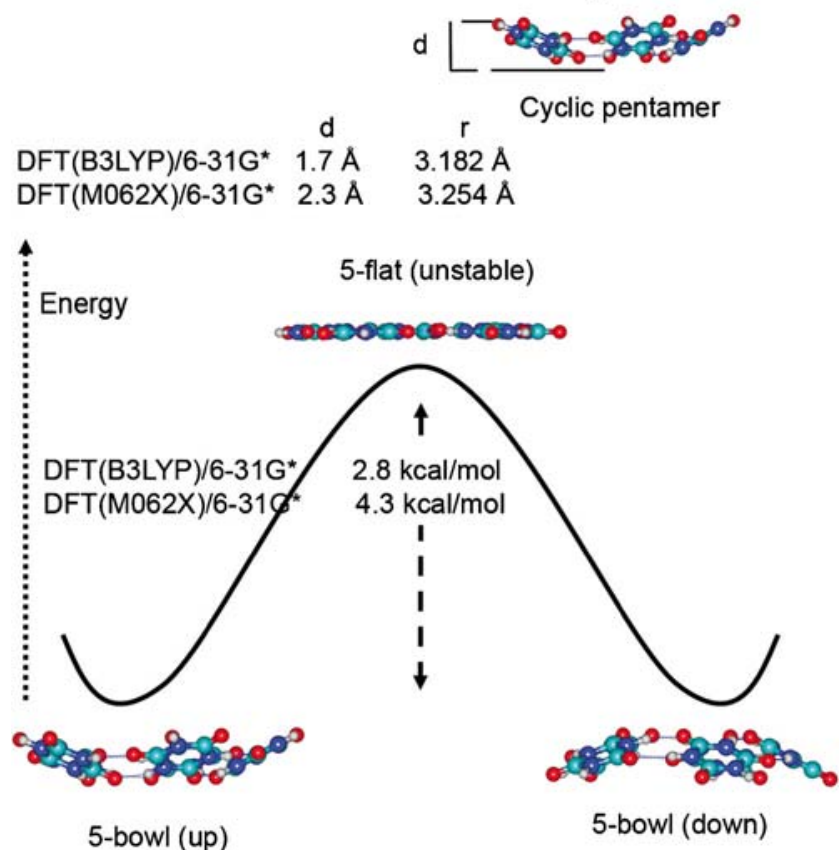

Figure 4. Bowl and flat shapes of $(\mathrm{CA})_{5}$ and geometrical features as obtained from DFT(B3LYP)/6-31G* and DFT(M062X)/6-31G* calculations.

Table 2. Geometrical parameters of $(\mathrm{CA})_{n}(n=1-6$ and 20) clusters, obtained from DFT(B3LYP)/6-31G* calculations.

\begin{tabular}{|c|c|c|c|c|}
\hline \multicolumn{2}{|l|}{ Cluster } & N-H (̊) & $(\mathrm{N}) \mathrm{H} . \ldots \mathrm{O}(\AA)$ & $\angle \mathrm{N}-\mathrm{H} \ldots \mathrm{OO}\left(^{\circ}\right)$ \\
\hline \multicolumn{2}{|l|}{2} & 1.029 & 1.851 & 170.0 \\
\hline \multicolumn{2}{|l|}{3} & $1.024-1.029$ & $1.831-1.855$ & $170.0-179.5$ \\
\hline \multicolumn{2}{|l|}{4} & $1.022-1.030$ & $1.850-1.865$ & $170.0-177.0$ \\
\hline \multirow[t]{2}{*}{ 5-bowl } & Inner & 1.031 & 1.791 & 168.5 \\
\hline & Outer & 1.027 & 1.950 & 163.1 \\
\hline \multirow[t]{2}{*}{ 6-flat } & Inner & 1.031 & 1.844 & 169.0 \\
\hline & Outer & 1.029 & 1.845 & 169.8 \\
\hline \multicolumn{2}{|c|}{ 20-ball } & 1.033 & 2.005 & 158.0 \\
\hline
\end{tabular}

$4.3 \mathrm{kcal} / \mathrm{mol}$ at the DFT(M062X)/6-31G* level. The $\mathrm{H}$-bond length and angles of CA clusters are listed in Table 2. It should be noted that there are two sets of $\mathrm{H}$-bonds in 5-bowl: inner and outer H-bonds. The inner $\mathrm{H}$-bonds are shorter than the outer H-bonds.

The optimized structure of cyclic hexamer (6-flat) at the DFT(B3LYP)/6-31G* level shows that it is the most stable when compared to other possible conformations. There is a central cavity with a radius of 
$3.90 \AA$. There are two sets of H-bonds in 6-flat hexamer also, inner and outer H-bonds. Unlike the 5-bowl, the inner and outer $\mathrm{H}$-bonds of 6-flat have nearly identical geometrical parameters.

Addition of CA molecules to the cyclic pentamer 5-bowl can result in larger bowls and eventually a ball as illustrated in Figure 5. In (CA $)_{20}$ ball structure, all the sixty N-H. . .O hydrogen bonds have identical geometrical parameters $(r \mathrm{~N}-\mathrm{H} . . \mathrm{O}=2.005 \AA$ and $\angle \mathrm{N}-\mathrm{H}$. . . O $\left.=158.0^{\circ}\right)$. The radius of the ball is calculated to be $16.8 \AA$ at HF/6-31G* level of theory, compared to $7.1 \AA$ for fullerene, $11.0 \AA$ for boric acid ball and $13.2 \AA$ for

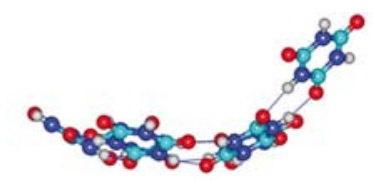

6-bowl

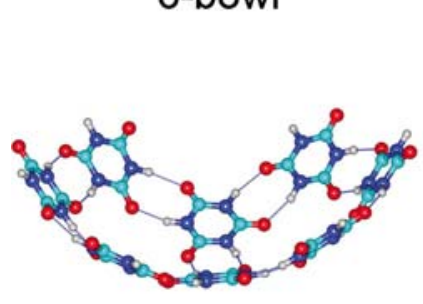

8-bowl

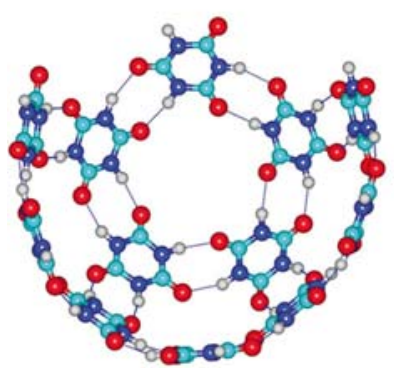

12-bowl
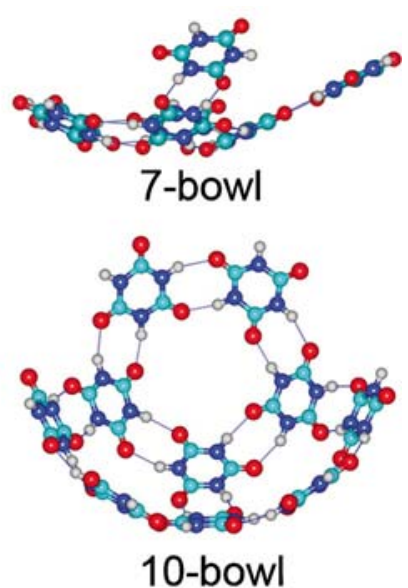

(a)

metaboric acid ball. Addition of any CA molecule to the flat hexamer retains the planarity. Figure 6 presents the 6-flat based sheet structure containing 20 CA molecules. Although the cyclic hexamer based clusters are planar, the inclusion of a 5-bowl leads to the formation of nonplanar structures. As a result, $(\mathrm{CA})_{24}$ is an ellipsoid as shown in Figure 6.

The variation in the stabilization energy per monomer $(\mathrm{SE} / n)$, with an increase in the size of the CA bowls and balls is plotted in Figure 7. SE/ $n$ increases linearly with increase in $n$, thus indicating the higher stability of larger bowls and balls. It is important to
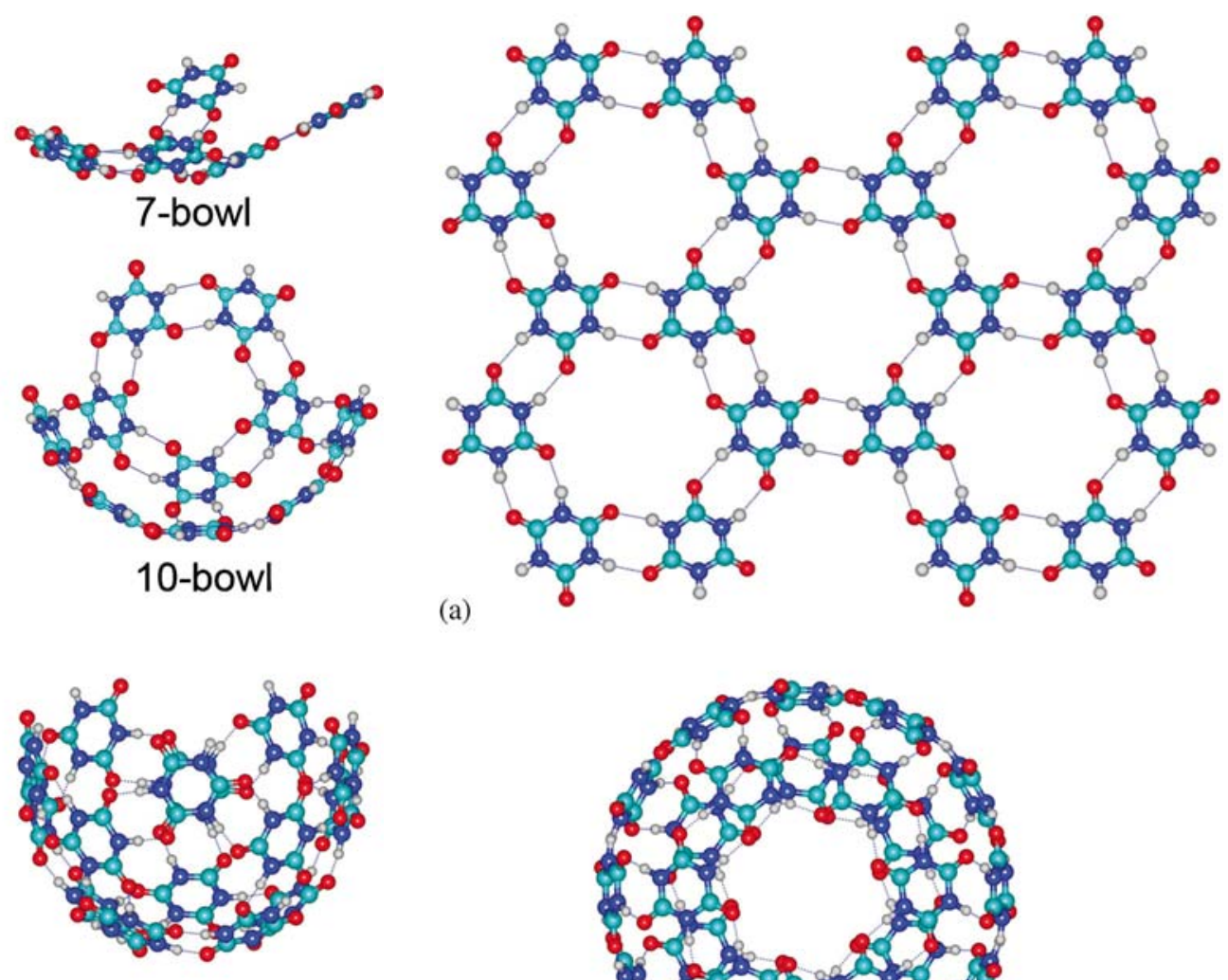

15-bowl

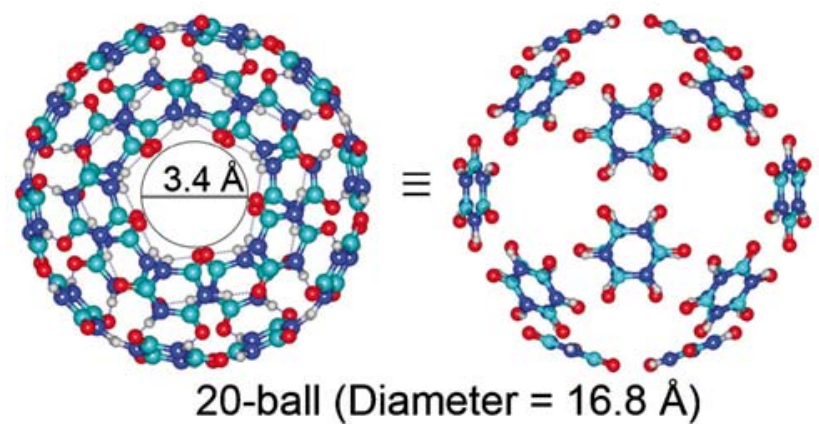

Figure 5. Optimized geometries of bowls and a ball of 5-bowl based clusters obtained from DFT(M062X)/6-31G* level of calculations. (b)
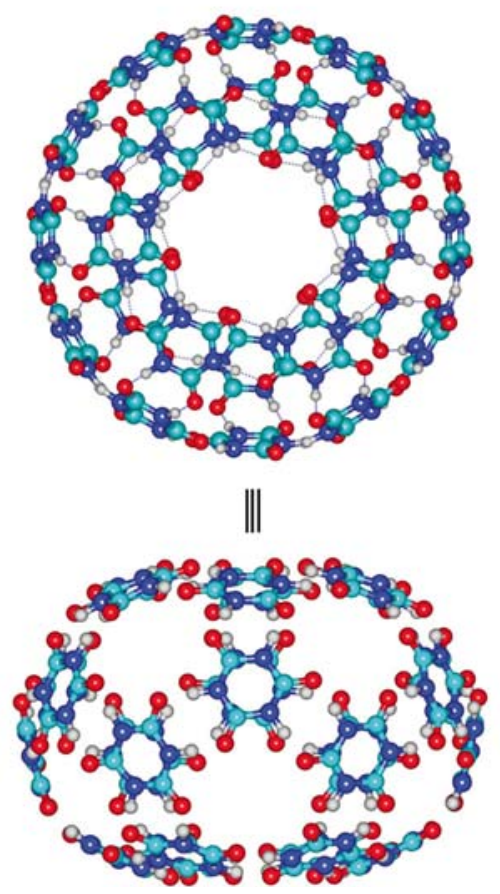

Figure 6. (a) Optimized geometry of cyanuric acid 20sheet as obtained from DFT(M062X)/6-31G* calculations; (b) Optimized geometry of 6-flat based ball obtained from DFT(M062X)/6-31G*calculations. 


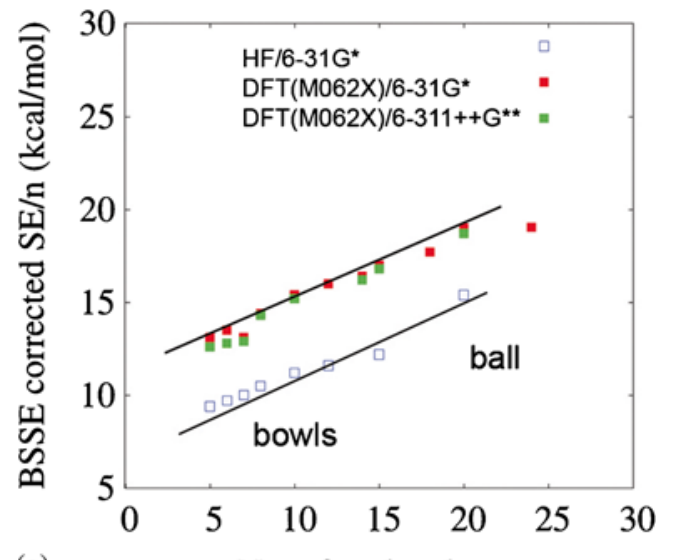

(a)

No. of molecules, $\mathrm{n}$

(b)

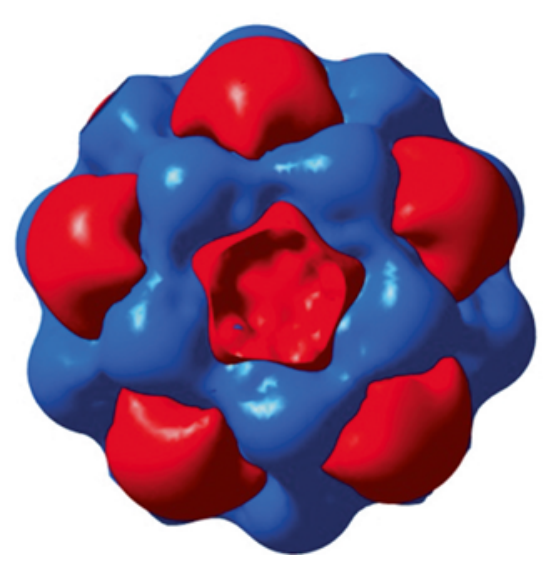

Figure 7. (a) Plot of variation in the BSSE-corrected $(\mathrm{SE} / n)$ value with an increase in the size of the CA cluster as obtained from HF/6-31G*, DFT(M062X)/6-31G* and DFT(M062X)/6-311++G** calculations; (b) Molecular electrostatic potential map of 20-ball obtained from HF/6$31 \mathrm{G}^{*}$ calculations. The red color represents the $-0.01 \mathrm{au}$ isosurface, while the blue represents the +0.01 au isosurface.

point out that the 20-ball and 24-ball have similar stability per monomer. This shows that the balls are much more stable than the bowl structures. However, there is no significant improvement in the stability per monomer between different ball structures.
Table 4. Electron density and Laplacian of electron density at the hydrogen bonding critical points for $(\mathrm{CA})_{n=2-6,20}$ clusters obtained from HF/6-31G* calculations.

\begin{tabular}{lccc}
\hline Cluster & $\begin{array}{c}\text { H-bonding } \\
\text { type }\end{array}$ & $\begin{array}{c}\text { Electron } \\
\text { density }\left(\mathrm{e} / \mathrm{a}_{\mathrm{o}}^{3}\right)\end{array}$ & $\begin{array}{c}\text { Laplacian of } \\
\text { electron density } \\
\left(\mathrm{e} / \mathrm{a}_{\mathrm{o}}^{5}\right)\end{array}$ \\
\hline 2 & & 0.021 & 0.020 \\
3 & & 0.022 & 0.023 \\
4 & & 0.023 & 0.021 \\
5-bowl & Inner OH. .O & 0.025 & 0.016 \\
& Outer OH...O & 0.024 & 0.015 \\
6-flat & Inner OH...O & 0.022 & 0.020 \\
& Outer OH...O & 0.022 & 0.020 \\
20-ball & & 0.023 & 0.021 \\
\hline
\end{tabular}

\subsection{Vibrational Frequency Analysis}

The scaled symmetric (ss) and asymmetric (as) N-H stretching frequency values for $\mathrm{CA}$ and its clusters up to $n=6$ at HF/6-31G* level are reported in Table 3. The calculated values for CA are $3454(\mathrm{ss})$ and $3451 \mathrm{~cm}^{-1}$ (as) when compared to the experimental values of 3060 and 3210, respectively. N-H stretching frequencies for the dimer 2A are 3314 (ss) and $3330 \mathrm{~cm}^{-1}$ (as) and the experimental values are 3257 and $3356 \mathrm{~cm}^{-1}$, respectively. The computed red-shifts in the ss and as frequencies in going from the monomer to the dimer are 140 and $121 \mathrm{~cm}^{-1}$, thus indicating the presence of H-bonds. The calculated red shifts for the trimer and the tetramer range from 103 to $147 \mathrm{~cm}^{-1}$. Due to a marginal variation in the geometrical parameters for inner and outer H-bonds in 5-bowl and 6-flat, the corresponding computed red shifts are also marginally different. $\mathrm{H}$-bonding in the inner periphery results in larger red shifts than the H-bonding in the outer periphery for both 5-bowl and 6-flat clusters. The calculated frequencies are all positive confirming that the reported clusters are all minima on the potential energy surface.

Table 3. Calculated vibrational frequencies of various $(\mathrm{CA})_{n}$ clusters at the HF/6$31 \mathrm{G}^{*}$ level of theory, along with the computed red shifts in the N-H stretching mode, ${ }^{\mathrm{a}}$ after scaling by a factor of 0.8929 . Values in parentheses are from experiment. ${ }^{25}$

\begin{tabular}{|c|c|c|c|c|c|}
\hline \multirow[b]{2}{*}{ Cluster } & & \multicolumn{2}{|c|}{${ }^{\text {a }}$ Scaled frequencies $\left(\mathrm{cm}^{-1}\right)$} & \multicolumn{2}{|c|}{ Red shift $\left(\mathrm{cm}^{-1}\right)$} \\
\hline & & ss & as & SS & As \\
\hline CA & & $3454(3060)$ & $3451(3210)$ & Nil & Nil \\
\hline 2 & & $3314(3257)$ & $3330(3356)$ & 140 & 121 \\
\hline 3 & & 3336 & 3348 & 118 & 103 \\
\hline 4 & Type I & $3306-3310$ & 3319-3335 & $144-147$ & $116-132$ \\
\hline \multirow[t]{2}{*}{ 5-bowl } & Inner & 3299 & $3306-3309$ & 154 & $142-146$ \\
\hline & Outer & 3343 & $3347-3352$ & 111 & $99-104$ \\
\hline \multirow[t]{2}{*}{ 6-flat } & Inner & 3306 & $3307-3308$ & 148 & $143-144$ \\
\hline & Outer & 3318 & $3324-3336$ & 136 & $115-127$ \\
\hline
\end{tabular}




\subsection{AIM Analysis}

The AIM theory has been used to characterize the $\mathrm{H}$ bonding and other non-bonding interactions in $(\mathrm{CA})_{\mathrm{n}}$, $n=2-6$ and 20 and the resulting electron density parameters are listed in Table 4. Figure 8 illustrates the AIM topology of $(\mathrm{CA})_{\mathrm{n}}$ clusters, where $n=2,5$ and 6. The values of electron density at the HBCPs fall in the range $0.021-0.025 \mathrm{e}_{\mathrm{o}}^{3}$. The calculated values
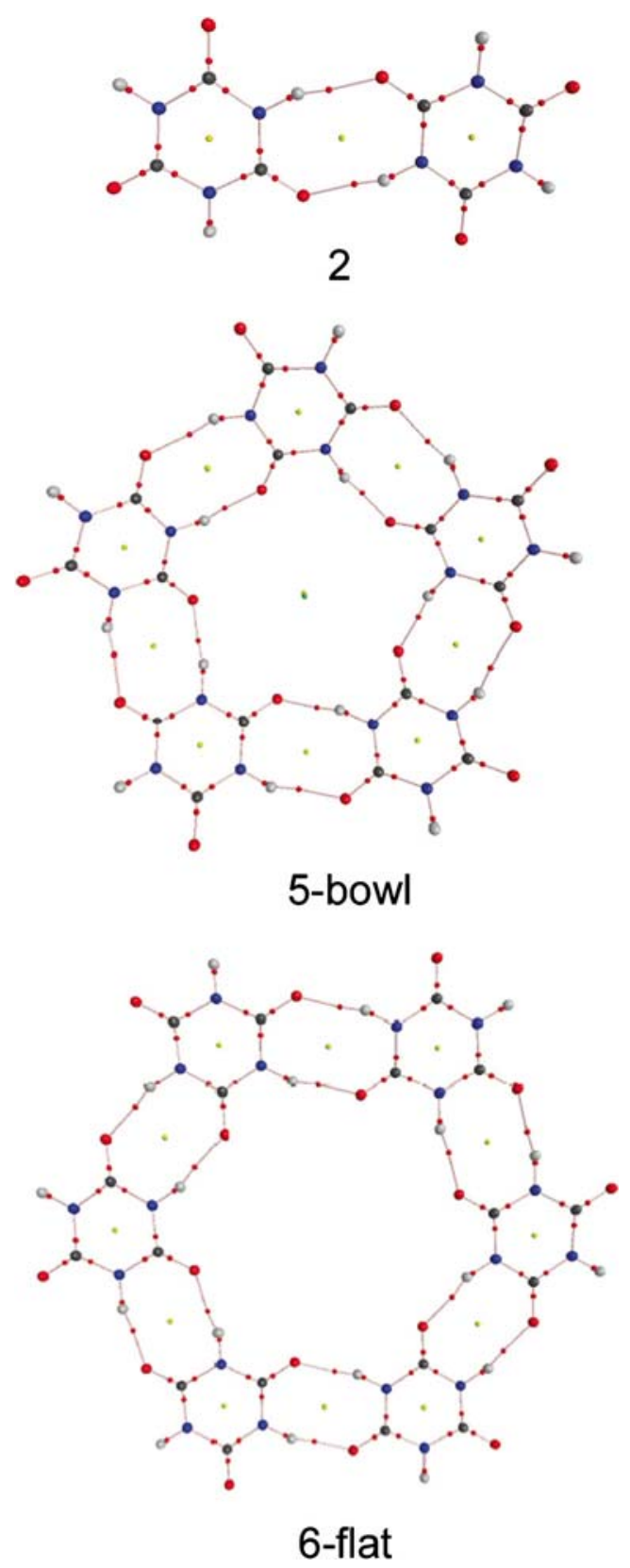

Figure 8. Atoms-in-molecules derived molecular topology of $(\mathrm{CA})_{2,5,6}$ clusters. The small red dots are bond critical points, small yellow dots are ring critical points. Large red spheres are oxygen atoms, large blue spheres are nitrogen atoms, large black spheres are carbon atoms and large grey spheres are hydrogen atoms. $\left(0.015-0.023 \mathrm{e} / \mathrm{a}_{\mathrm{o}}^{5}\right)$ of the Laplacian for all the H-bonds are positive, indicating the characteristics of $\mathrm{H}$-bonding interactions.

\subsection{MESP Analysis}

The molecular electrostatic potential (MESP) topography is a valuable tool to understand the reactivity of molecules. The \pm 0.01 au isosurfaces for $(\mathrm{CA})_{20}$ are shown in Figure 7. It is to be noted that the negative valued MESP features are seen at the centre of the cavity of cyclic pentamer units, while the positive MESP values are observed above each CA molecule. Therefore, it is possible to encapsulate molecules inside the $(\mathrm{CA})_{20}$ cage. However, there is a significant difference between the $(\mathrm{CA})_{20}$ ball, and the $(\mathrm{BA})_{20}$ and $(\mathrm{MBA})_{20}$. The latter two are fullerene-like. The cavity in the surface of $(\mathrm{BA})_{20}$ and $(\mathrm{MBA})_{20}$ is much smaller in size. Therefore it can be anticipated that much larger molecules can be trapped inside $(\mathrm{CA})_{20}$.

\section{Conclusions}

The present study reveals that CA forms a variety of H-bonded clusters. Among these clusters, 5-bowl and 6-flat are perhaps the most important structural motifs for the formation of ball and sheet structures similar to those found in BA and MBA clusters. It is shown that the hexamer can be non-planar, if it contains a 5-bowl. Clearly fullerene-like ball structures can be formed readily by CA. These balls can serve as hosts for atoms and molecules. A unified criterion for the formation of bowls and balls from basic molecular building blocks thus emerges from this study. It is proposed that any molecule having (i) a plane of symmetry $\sigma$, (ii) a principal rotational axis $C_{3} \perp \sigma$, and (iii) self-complementary hydrogen bonding regions has the ability to assemble into bowls and balls in addition to sheet structures.

\section{Acknowledgments}

This study has been supported by a grant from the Council of Scientific and Industrial Research, New Delhi. One of the authors (ME) thanks CSIR for financial assistance. NS is grateful to the Department of Science and Technology, New Delhi for a J. C. Bose National Fellowship. NS is an Honorary Professor at the Jawaharlal Nehru Centre for Advanced Scientific Research, Bengaluru.

\section{References}

1. Lehn J-M 1988 Supramolecular chemistry-scope and perspectives molecules, supermolecules, and molecular devices(Nobel lecture) Angew. Chem. Int. Ed. Engl. 2789 
2. Atwood J L and Steed J W 2004 In Encyclopedia of Supramolecular Chemistry (New York: M. Dekker, Inc)

3. Steed J W and Gale P A 2012 In Supramolecular chemistry: From molecules to nanomaterials (New York: Wiley)

4. Desiraju G R 2007 Crystal engineering: A holistic view Angew. Chem. Int. Ed. Engl. 468342

5. Jeffrey G A 1997 In An introduction to hydrogen bonding (New York: Oxford University Press)

6. Jeffrey G A and Saenger W 1994 In Hydrogen bonding in biological structures (New York: Springer-Verlag)

7. Desiraju G R and Steiner T 2001 In The Weak Hydrogen Bond: In Structural Chemistry and Biology (New York: Oxford University Press)

8. Elango M, Parthasarathi R, Subramanian V and Sathyamurthy N 2005 Bowls, balls and sheets of boric acid clusters: The role of pentagon and hexagon motifs J. Phys. Chem. A 1098587

9. Elango M, Subramanian V and Sathyamurthy N 2008 The self-assembly of metaboric acid molecules into bowls, balls and sheets J. Phys. Chem. A 1128107

10. Elango M, Subramanian V, Rahalkar A P, Gadre S R and Sathyamurthy N 2008 Structure, energetics, and reactivity of boric acid nanotubes: A molecular tailoring approach J. Phys. Chem. A 1127699

11. Ranganathan A, Pedireddi V R and Rao C N R 1999 Hydrothermal synthesis of organic channel structures: $1: 1$ hydrogen-bonded adducts of melamine with cyanuric and trithiocyanuric acids J. Am. Chem. Soc. 1211752

12. Liang X Q, Pu X M, Zhou H W, Wong N B and Tian A N 2007 Keto-enol tautomerization of cyanuric acid in the gas phase and in water and methanol J. Mol. Struc.Theochem. 816125

13. Kannappan K, Werblowsky $\mathrm{T}$ L, Rim K T, Berne B J and Flynn G W 2007 An experimental and theoretical study of the formation of nanostructures of self-assembled cyanuric acid through hydrogen bond networks on graphite J. Phys. Chem. B 1116634

14. Martsinovich N and Kantorovich L 2008 Comparative Theoretical Study of O- and S-Containing HydrogenBonded Supramolecular Structures J. Phys. Chem. C 11217340

15. Frisch M J, Trucks G W, Schlegel H B, Scuseria G E, Robb M A, Cheeseman J R, Scalmani G, Barone V, Mennucci B, Petersson G A, Nakatsuji H, Caricato M, Li X, Hratchian H P, Izmaylov A F, Bloino J, Zheng G, Sonnenberg J L, Hada M, Ehara M, Toyota K, Fukuda R, Hasegawa J, Ishida M, Nakajima T, Honda Y,
Kitao O, Nakai H, Vreven T, Montgomery Jr. J A, Peralta J E, Ogliaro F, Bearpark M J, Heyd J, Brothers E N, Kudin K N, Staroverov V N, Kobayashi R, Normand J, Raghavachari K, Rendell A P, Burant J C, Iyengar S S, Tomasi J, Cossi M, Rega N, Millam N J, Klene M, Knox J E, Cross J B, Bakken V, Adamo C, Jaramillo J, Gomperts R, Stratmann R E, Yazyev O, Austin A J, Cammi R, Pomelli C, Ochterski J W, Martin R L, Morokuma K, Zakrzewski V G, Voth G A, Salvador P, Dannenberg J J, Dapprich S, Daniels A D, Farkas Ö, Foresman J B, Ortiz J V, Cioslowski J and Fox D J 2009 Gaussian 09. Wallingford, CT, USA: Gaussian, Inc.

16. Boys S F and Bernardi F 1970 The calculation of small molecular interactions by the differences of separate total energies. Some procedures with reduced errors Mol. Phys. 19553

17. Scott A P and Radom L 1996 Harmonic Vibrational Frequencies: An Evaluation of Hartree-Fock, MøllerPlesset, Quadratic Configuration Interaction, Density Functional Theory, and Semiempirical Scale Factors $J$. Phys. Chem. 10016502

18. Fogarasi G and Pulay P 1984 AB Initio Vibrational Force Fields Annu. Rev. Phys. Chem. 35191

19. Bader R F W 1994 In Atoms in molecules: A quantum theory (Oxford: Clarendon Press)

20. Biegler-Konig F, Schonbohm J, Derdau R, Bayles D and Bader R F W 2000 AIM 2000. Bielefeld, Germany

21. Gadre S R and Shirsat R N 2000 In Electrostatics of Atoms and Molecules (Hyderabad: Universities Press)

22. Murray J S and Sen K 1996 In Molecular electrostatic potentials: Concepts and applications (Amsterdam: Elsevier Science)

23. Chen Z, Wannere C S, Corminboeuf C, Puchta R and Schleyer P v R 2005 Nucleus-Independent Chemical Shifts (NICS) as an aromaticity criterion Chem. Rev. 1053842

24. Klotz I M and Askounis T 1947 Absorption spectra and tautomerism of cyanuric acid, melamine and some related compounds J. Am. Chem. Soc. 69801

25. Newman R and Badger R M 1952 Infrared spectra of cyanuric acid and deutero cyanuric acid1 J. Am. Chem. Soc. $\mathbf{7 4} 3545$

26. Coppens P and Vos A 1971 Electron density distribution in cyanuric acid. II. Neutron diffraction study at liquid nitrogen temperature and comparison of X-ray neutron diffraction results Acta Crystallogr. B 27146

27. Wiebenga E H 1952 Crystal structure of cyanuric acid J. Am. Chem. Soc. 746156 